\title{
Desempenho de genótipos de soja nas condições edafoclimáticas do ecótono Cerrado-Pantanal
}

\author{
Performance of soybean genotypes in soil and climatic conditions of the \\ Cerrado-Pantanal ecotone
}

\section{Performance des génotypes de soja dans le sol et les conditions climatiques de la ecotone Cerrado-Pantanal}

\author{
El rendimiento de genotipos de soya en el suelo y las condiciones climáticas del ecotono \\ Cerrado-Pantanal
}

Francisco Eduardo Torres*

(feduardo@uems.br)
Edimilson Carvalho da Silva*
(edmilson_carvalho@yahoo.com.br)
Paulo Eduardo Teodoro*
(eduteodoro@hotmail.com)

Recebido em 10/07/2012; revisado e aprovado em 10/05/2013; aceito em 07/08/2013

\begin{abstract}
Resumo: O ecótono Cerrado-Pantanal é uma extensa região que, por suas características edafoclimáticas serem diferentes das principais regiões produtoras de grãos dos estados de Mato Grosso do Sul e Mato Grosso, ficaram alijadas dos programas de melhoramento genético de muitas culturas, como a soja. Com isso, este trabalho teve como objetivo avaliar o desempenho de cinco cultivares de soja, e indicar aqueles com melhor adaptação para o cultivo na região de Aquidauana, MS. O trabalho foi realizado na área experimental da Universidade Estadual de Mato Grosso do Sul, Unidade de Aquidauana, no ano agrícola 2010/2011, em sistema plantio direto. O delineamento experimental utilizado foi o inteiramente casualizado, com 5 tratamentos (BMX Magna RR, Monsoy 7908 RR, Nidera 7321 RG, BRS 245 RR e Syngenta 3358 RR) e 4 repetições. Tendo em vista que a maioria dos genótipos avaliados obteve desempenho satisfatório, infere-se que as condições edafoclimáticas dessa região são favoráveis ao cultivo da soja. O genótipo BRS 245 apresentou o maior valor absoluto de produtividade, com uma média aproximada de 3.383,33 $\mathrm{kg} \mathrm{ha}^{-1}$, porém não se diferiu estatisticamente dos demais genótipos, servindo de sugestão para o estabelecimento de uma nova prática econômica na região de Aquidauana.
\end{abstract}

Palavras-chave: Caracteres agronômicos. Glycine max. Produtividade.

Abstract: The ecotone Cerrado-Pantanal is a vast region which are different soil and climatic characteristics of the major grain producing regions in the states of Mato Grosso and Mato Grosso do Sul, were shut out of the breeding programs of many crops, such as soybeans. With that, this study aimed to evaluate the performance of five soybean, and indicate those best adapted for cultivation in the region Aquidauna-MS. The study was conducted at the experimental area of the State University of Mato Grosso do Sul, Unit Aquidauna in the agricultural year 2010/2011, in tillage. The experimental design was a completely randomized design with 5 treatments and 4 replications. Five genotypes were used (RR BMX Magna, Monsoy 7908 RR, RG Nidera 7321, BRS 245 RR 3358 RR and Syngenta), given that the majority of the genotypes had seemingly good performance, showing that the conditions of soil and climate of the region are favorable for soybean cultivation. Being BRS 245 RR showed the highest absolute value of productivity with an approximate average of $3,383.33 \mathrm{~kg} \mathrm{ha}^{-1}$, but not statistically different from other genotypes, serving suggestion that would establish a new activity economic in the region of Aquidauna.

Key words: Agronomic characters. Glycine max. Productivity.

Résumé: Le ecotone Cerrado-Pantanal est une vaste région qui sont différents sols et les caractéristiques climatiques de la majeure grain régions dans les Etats du Mato Grosso et du Mato Grosso do Sul production, étaient exclus des programmes de reproduction de nombreuses cultures, comme le soja. Avec cela, cette étude visait à évaluer la performance des cinq soja, et d'indiquer les mieux adaptés à la culture dans la région Aquidauna-MS. L'étude a été menée dans la zone expérimentale de l'Université d'État du Mato Grosso do Sul, Aquidauna de l'unité dans la campagne agricole 2010/2011, du travail du sol. Le dispositif expérimental était un dispositif complètement aléatoire avec 5 traitements et 4 répétitions. Cinq génotypes ont été utilisés (RR BMX Magna, Monsoy 7908 RR, RG Nidera 7321, BRS 245 RR 3358 RR et Syngenta), étant donné que la majorité des génotypes avait apparemment de bonnes performances, démontrant que les conditions de sol et le climat de la région sont favorables à la culture du soja. Être BRS 245 RR a montré la plus grande valeur absolue de la productivité avec une moyenne approximative de $3383,33 \mathrm{~kg} \mathrm{ha}^{-1}$, mais pas statistiquement différent des autres génotypes, servant suggestion, qui permettraient d'établir une nouvelle activité économique dans la région de Aquidauna.

Mots-clés: Caractères agronomiques. Glycine max. Productivité.

\footnotetext{
* Universidade Estadual de Mato Grosso do Sul, Unidade Universitária de Aquidauana (UEMS/UUA), Aquidauana, MS, Brasil.
} 
Resumen: El ecotono Cerrado-Pantanal es una vasta región que son diferentes del suelo y las características climáticas de las principales regiones productoras de cereales en los estados de Mato Grosso y Mato Grosso do Sul, fueron excluidos de los programas de mejora genética de muchos cultivos, como la soja. Con ello, este estudio tuvo como objetivo evaluar el desempeño de cinco soja, e indicar los mejor adaptados para el cultivo en la región Aquidauana, MS. El estudio se realizó en el área experimental de la Universidad del Estado de Mato Grosso do Sul, Aquidauana Unidad en el año agrícola 2010/2011, en la labranza. El diseño experimental fue un diseño completamente al azar con 5 tratamientos y 4 repeticiones. Se utilizaron cinco genotipos (RR BMX Magna, Monsoy 7908 RR, RG Nidera 7321, BRS 245 RR 3358 RR y Syngenta), dado que la mayoría de los genotipos tuvo aparentemente un buen rendimiento, que muestra que las condiciones de suelo y clima de la región son favorables para el cultivo de soja. Ser BRS 245 RR mostró el mayor valor absoluto de la productividad con una media aproximada de 3,383.33 $\mathrm{kg} \mathrm{ha}^{-1}$, pero no estadísticamente diferente de otras variedades, sirviendo sugerencia, que establecería una nueva actividad económica en la región de Aquidauana.

Palabras clave: Caracteres agronómicos. Glycine max. Productividad.

\section{Introdução}

A soja (Glycine max L.) é considerada uma fonte de proteína completa, isto é, contém quantidades significativas da maioria dos aminoácidos essenciais que devem ser providos ao corpo humano através de fontes externas, por causa de sua inabilidade para sintetizá-los. No contexto mundial, o Brasil possui significativa participação na oferta e na demanda de produtos do complexo agroindustrial da soja, o qual vem desempenhando papel fundamental para o desenvolvimento de várias regiões do país (EMBRAPA, 2004).

O Brasil é o segundo maior produtor de soja do mundo, perdendo apenas para os Estados Unidos, porém sendo o país com a maior média de produtividade de grãos e o maior exportador mundial de grão e farelo. Na safra 2010/2011, a produção brasileira chegou a 75,0 milhões de toneladas, com uma área plantada de 24,2 milhões de hectares, atingindo uma produtividade média de 3106 $\mathrm{Kg}_{\mathrm{ga}}{ }^{-1}$. Os números do Paraná são os de maior destaque, com $3.240 \mathrm{Kg} \mathrm{ha}^{-1}$, a melhor produtividade de soja em todo o país nessa safra. O maior estado produtor é o Estado de Mato Grosso, com uma produção de 20,4 milhões de toneladas de grãos, em uma área cultivada de 6,4 milhões de hectares, com uma produtividade de grãos média de 3.190 $\mathrm{Kg} \mathrm{ha}^{-1}$ (EMBRAPA, 2009).

O estado de Mato Grosso do Sul, na safra 2010/2011, ocupou o quinto lugar no ranking dos Estados que mais produzem soja no Brasil. A produção chegou aos 5,0 milhões de toneladas de grãos, em uma área de 1,7 milhões de hectares, atingindo uma produtividade média de $2.866 \mathrm{Kg} \mathrm{ha}^{-1}$ de grãos (CONAB, 2011).
A região do ecótono Cerrado-Pantanal tem sua economia baseada na produção rural, indústria, extração mineral, turismo e prestação de serviços, sendo sua principal atividade econômica a pecuária extensiva de cria e recria, com destaque para a de corte, em uma área de 949.694 hectares de pastagem natural, e 810.790 cabeças de bovinos. Diferente da pecuária, a atividade agrícola contribui com 9.492 hectares, onde se destaca o cultivo de milho, mandioca e olerícolas (IBGE, 2010).

As condições de riscos e incertezas na agricultura são elevadas e, para administrá-las, cabe ao produtor rural tomar decisões baseadas em informações técnicas e econômicas. Dentre as diversas práticas culturais, a utilização de genótipos adaptados ao local de cultivo é de extrema importância, por determinarem melhor aproveitamento de fatores abióticos como água, luz e nutrientes, para que a cultura possa expressar todo o seu potencial (ARGENTA et al., 2001).

A região do ecótono Cerrado-Pantanal, comparada com outras regiões produtoras de grãos, tem poucas recomendações de cultivares de soja devido à baixa prática dessa atividade na região, havendo uma grande necessidade de estudos voltados para determinação de genótipos adaptados, uma vez que as cultivares, quando lançadas no mercado, são avaliadas em localidades em que a prática da agricultura é mais intensa. Sendo assim, tais estudos são de grande importância para as regiões onde essa atividade é pouco praticada (IBGE, 2010; EMBRAPA, 2004).

Nesse contexto, o objetivo deste trabalho foi avaliar o desempenho de genótipos de soja no município de Aquidauana, a fim de se identificar aquelas que possam ser cultivadas na região. 


\section{Metodologia}

O trabalho foi desenvolvido na Universidade Estadual de Mato Grosso do Sul, no campo experimental da Unidade Universitária de Aquidauana, com coordenadas geográficas $20^{\circ} 20^{\prime}$ Sul, $55^{\circ} 48^{\prime}$ Oeste e altitude média de 149 metros. O clima regional é classificado, pelo sistema inter- nacional de Köppen-Geigher, como “Tropical quente-úmido" (Aw), com precipitação média anual de $1.250 \mathrm{~mm}$ e temperatura média anual de $26^{\circ} \mathrm{C}$ (SCHIAVO et al., 2010).

O solo é classificado como Argissolo-Vermelho distrófico (EMBRAPA, 2006), fisicamente profundo, com textura arenosa, moderadamente drenada, levemente inclinada e com boa fertilidade (Tabela 1).

Tabela 1 - Análise química do solo da área experimental da UEMS, Aquidauana, MS.

\begin{tabular}{cccccccccccc}
\hline $\mathrm{pH}$ & $\mathrm{MO}$ & $\mathrm{P}$ & $\mathrm{H}+\mathrm{Al}$ & $\mathrm{Al}$ & $\mathrm{Ca}$ & $\mathrm{MGMg}$ & $\mathrm{Na}$ & $\mathrm{K}$ & $\mathrm{SB}$ & $\mathrm{CTC}$ & $\mathrm{V} \%$ \\
\hline & $\left(\mathrm{g} \mathrm{kg}^{-1}\right)$ & $\left(\mathrm{mg} \mathrm{kg}^{-1}\right)$ & & - & -0 & -0 & -0 & -0 & \\
6,36 & 10,53 & 65,09 & 1,8 & 0,2 & 3,3 & 1,7 & 1,39 & 0,01 & 6,4 & 8,2 & 78,05 \\
\hline
\end{tabular}

O presente trabalho foi conduzido nos meses de novembro de 2010 a abril de 2011, sendo avaliados os seguintes cultivares: BMX Magna (ciclo precoce, hábito de crescimento indeterminado e porte médio); Monsoy 7908 (ciclo precoce, hábito de crescimento determinado e porte médio); Nidera 7321 (ciclo médio, hábito de crescimento indeterminado e porte alto); BRS 245 (ciclo semiprecoce, hábito de crescimento determinado e porte médio) e Syngenta 3358 (ciclo médio, hábito de crescimento indeterminado e porte alto), sendo todas geneticamente modificadas, tolerantes à molécula de Glyphosate presente no herbicida Roundup Ready, pois contém o gene RR.

Foi utilizado no experimento o delineamento experimental inteiramente casualizado, com cinco tratamentos (genótipos) e quatro repetições. As parcelas foram compostas por 6 linhas de $10 \mathrm{~m}$, espaçadas $0,45 \mathrm{~m}$ uma da outra, onde a área útil foi constituída pelas duas linhas centrais descontando-se um metro de cada extremidade. O experimento foi instalado em sistema de plantio direto após dessecação da vegetação remanescente dos restos culturais do milho safrinha cultivado anteriormente na área.

A semeadura das cultivares foi realizada mecanicamente com uma semeadora de 3 linhas, no dia 19 de novembro de 2010. Na semeadura foram adicionados $300 \mathrm{Kg} \mathrm{ha}^{-1}$ de adubo químico da fórmula 04-30-10, utilizando uma densidade de 18 a 20 sementes por metro linear. O controle de plantas daninhas foi realizado por meio da aplicação de $3 \mathrm{~L} \mathrm{ha}^{-1}$ de Glyphosate aos 30 dias após a semeadura (DAE).

O tratamento de sementes foi realizado utilizando-se $100 \mathrm{~mL} \mathrm{ha}^{-1}$ do produto químico inseticida e fungicida de ingredientes ativos Fipronil $250 \mathrm{~g} \mathrm{~L}^{-1}+$ Piraclostrobina $25 \mathrm{~g} \mathrm{~L}^{-1}+$ Thiophanate methyl $225 \mathrm{~g} \mathrm{~L}^{-1}$, o que garantiu, assim, a sanidade das sementes e das plântulas nos primeiros dias após semeadura, prevenindo a semente contra pragas do solo e algumas doenças. No tratamento de sementes, também foram utilizados inoculantes tipo turfa na dose de 100 gramas do produto para cada 1 quilograma de semente tratada, para auxiliar na fixação biológica de nitrogênio.

Durante o desenvolvimento da cultura, foi realizada uma aplicação de $70 \mathrm{~mL} \mathrm{ha}^{-1} \mathrm{do}$ produto químico inseticida Diflubenzuron $240 \mathrm{~g} \mathrm{~L}^{-1}$, para realizar o controle da lagarta da soja (Anticarsia gemmatalis) no período do estádio vegetativo V5 (quarta folha trifoliolada completamente desenvolvida), aos 40 dias após a emergência da cultura.

No período reprodutivo, foi feita uma aplicação de $0,7 \mathrm{~L} \mathrm{ha}^{-1}$ do produto químico Endossulfan, $350 \mathrm{~g} \mathrm{~L}^{-1}$, para realizar o controle da lagarta da soja (Anticarsia gemmatalis), percevejo marrom (Euschistus heros), percevejo verde (Nezara viridula) e percevejo-verdepequeno-da-soja (Piezodorus guildinii) no período reprodutivo $\mathrm{R} 2$ (florescimento pleno).

Em conjunto foi realizada a aplicação de $200 \mathrm{~mL} \mathrm{ha}^{-1}$ do fungicida Azoxystrobin $200 \mathrm{~g} \mathrm{~L}^{-1}+$ Ciproconazol $80 \mathrm{~g} \mathrm{~L}^{-1}$, para realizar o controle e prevenção de doenças como a antracnose (Colletotrichum truncatum), doença 
de final de ciclo (Corynespora cassiicola), ferrugem asiática (Phakopsora pachyrhizi), mancha parda (Septoria glycines), oídio (Microsphaera diffusa), dentre outras, garantindo a sanidade da cultura até o final do seu ciclo.

Foram avaliados os seguintes parâmetros:

- Altura de inserção da primeira vagem: foram colhidas aleatoriamente 10 plantas por parcela e feita contagem na própria área experimental com auxílio de uma régua graduada, medindo até o ponto de incisão da vagem na haste principal da planta.

- Altura de planta: foram colhidas 10 plantas, aleatoriamente, por parcela da área experimental, realizando-se a contagem na própria área experimental com auxílio de uma régua graduada em centímetros, para ajudar na medição das plantas.

- Número de ramificações por planta: foram coletadas aleatoriamente 10 plantas por parcela da área experimental, onde foram feitas as contagens de cada planta na própria área experimental.

- Número de vagens por planta: foram coletadas aleatoriamente 10 plantas por parcela da área experimental, onde foram feitas as contagens de cada planta na própria área experimental.

- Produtividade de grãos: foi realizada colheita manual da área útil de cada parcela, seguida da pesagem dos grãos e da leitura da umidade. Foi realizada a correção da umidade para $13 \%$ a fim de se estimar a produtividade em quilograma por hectare.

- Massa de cem grãos: foram retirados 100 grãos de cada amostra colhida e feita a pesagem em balança analítica, com quatro repetições por parcela.

Os dados foram submetidos à análise de variância e ao teste de comparação de médias de Duncan, ao nível de 5\% de significância, pelo aplicativo computacional Sas.

\section{Resultados e discussão}

Na Tabela 2, são apresentados os valores médios de altura da inserção da primeira vagem e o número médio de ramificações por planta de cada genótipo avaliado, em que foi verificada diferença significativa $(p>0,05 \%)$ apenas para o primeiro parâmetro.

Tabela 2 - Valores médios de altura da inserção da primeira vagem $(\mathrm{cm})$ e número de ramificações por planta, de cinco genótipos de soja cultivados em Aquidauana, MS, 2011.

\begin{tabular}{ccc}
\hline \multirow{2}{*}{ Genótipos } & Altura de inserção da primeira vagem & Número de ramificações \\
\cline { 2 - 3 } & $\bar{x} \pm \mathrm{SD} ; \mathrm{CV} \%$ & $\bar{x} \pm \mathrm{SD} ; \mathrm{CV} \%$ \\
\hline BRS 245 & $12,77 \mathrm{ab} \pm 1,10 ; 10,03 \%$ & $8,92 \mathrm{a} \pm 0,96 ; 13,83 \%$ \\
BMX Magna & $12,32 \mathrm{ab} \pm 1,16 ; 9,97 \%$ & $10,32 \mathrm{a} \pm 1,71 ; 20,69 \%$ \\
MonSoy 7908 & $11,05 \mathrm{~b} \pm 1,12 ; 10,50 \%$ & $8,87 \mathrm{a} \pm 1,13 ; 28,39 \%$ \\
Nidera 7321 & $12,30 \mathrm{ab} \pm 1,39 ; 13,56 \%$ & $8,32 \mathrm{a} \pm 1,32 ; 18,11 \%$ \\
Syngenta 3358 & $17,02 \mathrm{a} \pm 0,86 ; 6,56 \%$ & $13,82 \mathrm{a} \pm 0,23 ; 4,04 \%$ \\
\hline Média & 13,09 & 10,05 \\
\hline
\end{tabular}

$\bar{x}$ : média; SD: desvio padrão; CV: coeficiente de variação, onde letras iguais nas colunas não diferem, estatisticamente, entre si pelo teste de Duncan $(p>0,05)$.

A altura de inserção da primeira vagem de soja é uma característica agronômica importante à operação de colheita mecânica dos grãos. Essa variável deve ser de 10 a 13 $\mathrm{cm}$, para que se reduzam as perdas durante a colheita (QUEIROZ et al., 1981). Assim, com relação à média dos valores absolutos da altura de inserção da primeira vagem do presente experimento, independente da altitude e das condições edafoclimáticas da região, teve efeito positivo a cultivar Syngenta 3358 , obtendo a altura de $17,02 \mathrm{~cm}$, valor considerado elevado quando comparado com resultados das regiões produtoras de soja, cuja altitude é, em media, a partir de $400 \mathrm{~m}$ acima do nível do mar.

De acordo com os resultados alcançados, todos os genótipos avaliados apresentaram valores médios superiores à altura preconizada por Sediyama et al. (1985) que 
é de $10 \mathrm{~cm}$, e dentro das recomendações de Araújo Junior et al. (2009), que era de $11 \mathrm{~cm}$, e adequadas quando comparadas com o trabalho de Vernetti Junior et al. (2010). Assim, pode-se inferir que os genótipos avaliados neste experimento apresentaram altura de inserção da primeira vagem dentro das margens das recomendações para colheita mecanizada, em que esse fator não interferiu na adaptabilidade ou na produtividade das cultivares analisadas.

A altura da primeira vagem pode ser característica da própria cultivar, entretanto, quando o plantio é realizado em regiões com dias mais curtos, a altura da planta é reduzida, havendo tendência do desenvolvimento de vagens próximas ao solo. Os fatores ambientais ou práticas culturais que afetam a altura da planta também podem influenciar consideravelmente a altura da primeira vagem (SEDIYAMA et al., 1985).

Para Navarro Júnior e Costa (2002), o número de ramificações por planta é um importante componente do rendimento, uma vez que representa a maior superfície fotossintetizante, além do potencial produtivo de um genótipo. De acordo com Cervieri Filho (2005), esse parâmetro fisiológico pode sofrer alterações ano a ano em função das características edafoclimáticas do ambiente de cultivo.

Schuch et al. (2009) constataram que as sementes de soja com alta qualidade fisiológica produziram plantas com maior número de ramificação, sendo a média encontrada por estes autores (de 9 ramificações) inferior à obtida neste experimento, que foi de 10,05 ramificações por planta, mostrando que as cultivares não sofreram alterações morfológicas que comprometam sua adaptação ao ambiente em que foram implantadas.

Na Tabela 3, são apresentados os valores médios de número de vagem por planta e altura de planta, em que foi constada diferença significativa $(p<0,05 \%)$ entre os genótipos avaliados apenas para a segunda variável.

Tabela 3 - Valores médios de número de vagem por planta e altura de planta $(\mathrm{cm})$ de cinco genótipos de soja cultivados em Aquidauana, MS.

\begin{tabular}{ccc}
\hline \multirow{2}{*}{ Genótipos } & Número de vagem por planta & Altura de planta \\
\cline { 2 - 3 } & $\bar{x} \pm$ SD;CV $\%$ & $\bar{x} \pm$ SD; CV $\%$ \\
\hline BRS 245 & $79,47 \mathrm{a} \pm 9,48 ; 9,27 \%$ & $82,12 \mathrm{a} \pm 6,43 ; 8,23 \%$ \\
BMX Magna & $71,25 \mathrm{a} \pm 5,92 ; 8,69 \%$ & $76,82 \mathrm{ab} \pm 6,19 ; 8,18 \%$ \\
MonSoy 7908 & $82,70 \mathrm{a} \pm 9,58 ; 14,48 \%$ & $73,67 \mathrm{ab} \pm 5,67 ; 6,81 \%$ \\
Nidera 7321 & $60,52 \mathrm{a} \pm 11,41 ; 19,49 \%$ & $65,00 \mathrm{ab} \pm 5,07 ; 6,81 \%$ \\
Syngenta 3358 & $71,45 \mathrm{a} \pm 4,72 ; 7,27 \%$ & $63,90 \mathrm{~b} \pm 3,36 ; 3,50 \%$ \\
\hline Média & 73,08 & 72,30 \\
\hline
\end{tabular}

$\bar{x}$ : média; SD: desvio padrão; CV: coeficiente de variação, onde letras iguais nas colunas não diferem, estatisticamente, entre si pelo teste de Duncan $(p>0,05)$.

Rocha et al. (2001), estudando o comportamento de cultivares de soja em diferentes populações de plantas, observaram que o número de vagem por planta está intimamente ligado à densidade de plantio, de forma que plantios mais adensados tendem a diminuir o número de ramificações e, consequentemente, o número de vagens.

Os valores encontrados para número de vagens na planta foram satisfatórios, pois todos os genótipos do experimento apresentaram valores acima de 60 vagens por planta, superiores aos encontrados por Santos et al. (2007), que foram de 53, 55 e 60, para as culti- vares Monsoy 7908, BRS 245 e Syngenta 3358, respectivamente.

De acordo com Garcia (1979), citado por Peixoto et al. (2000), o número total de vagens não é o melhor indicador do rendimento total da cultura. Esse fato foi observado nesse experimento, pois o genótipo que apresentou maior número de vagens não foi o que apresentou maior produtividade de grãos.

Segundo Queiroz et al. (1981), a altura de planta é uma característica que influencia a colheita mecanizada. Valores considerados ótimos para colheita mecanizada devem estar acima de $60 \mathrm{~cm}$ (YOKOMIZO, 1999). 
Assim, todos os genótipos avaliados neste experimento apresentaram, para esse parâmetro, médias acima da que é considerada pela literatura como ótima para a colheita mecanizada.

Os resultados encontrados para altura de planta com as variedades BRS 245, BMX Magna e Nidera 7321 foram superiores aos encontrados pela Embrapa (2009), no município de Maracaju, MS, utilizando os mesmos genótipos. Os valores também se mostraram superiores aos encontrados pela Fundação
MS (2009), no município de Sidrolândia, MS, onde também se utilizaram esses materiais, indicando que os genótipos se adaptaram à região no que se refere ao tamanho das plantas, sendo a cultivar BRS 245 a que se sobressaiu dentre as demais nesse parâmetro, com a média $82,12 \mathrm{~cm}$.

Na Tabela 4, são apresentados os valores médios de massa de cem grãos e produtividade de grãos para os genótipos avaliados, em que não foi verificada diferença significativa $(p>0,05 \%)$ entre si.

Tabela 4 - Valores médios de massa de cem grãos (g) e Produtividade de grãos $\left(\mathrm{kg} \mathrm{ha}^{-1}\right)$ de cinco genótipos de soja cultivados em Aquidauana, MS, 2011.

\begin{tabular}{ccc}
\hline \multirow{2}{*}{ Genótipos } & Massa de cem grãos & Produtividade de grãos \\
\cline { 2 - 3 } & $\bar{x} \pm \mathrm{SD} ; \mathrm{CV} \%$ & $\bar{x} \pm \mathrm{SD} ; \mathrm{CV} \%$ \\
\hline BRS 245 & $21,70 \mathrm{a} \pm 0,23 ; 1,40 \%$ & $3.383,33 \mathrm{a} \pm 0,38 ; 14,77 \%$ \\
BMXMagna & $19,05 \mathrm{a} \pm 2,21 ; 13,75 \%$ & $3.145,66 \mathrm{a} \pm 0,56 ; 21,16 \%$ \\
MonSoy 7908 & $20,66 \mathrm{a} \pm 1,23 ; 5,43 \%$ & $2.700,56 \mathrm{a} \pm 0,32 ; 11,05 \%$ \\
Nidera 7321 & $20,70 \mathrm{a} \pm 0,66 ; 4,31 \%$ & $3.000,77 \mathrm{a} \pm 0,11 ; 8,35 \%$ \\
Syngenta 3358 & $20,78 \mathrm{a} \pm 2,33 ; 12,50 \%$ & $3.054,88 \mathrm{a} \pm 0,32 ; 10,04 \%$ \\
\hline Média & 20,58 & $3.057,04$ \\
\hline
\end{tabular}

$\bar{x}$ : média; SD: desvio padrão; CV: coeficiente de variação, onde letras iguais nas colunas não diferem, estatisticamente, entre si pelo teste de Duncan ( $p>0,05)$.

A massa de cem grãos é um caráter importante para a cultura da soja, pois, apesar de sofrer pouca influência do ambiente, do homem e dos tratos culturais, é fundamental para poder estimar a produtividade de grãos e a sanidade da lavoura, como também ajudar a identificar se o genótipo em questão adaptou-se às condições a que foi submetido.

A média final obtida neste experimento para massa de cem grãos $(20,58 \mathrm{~g})$ se mostrou superior às médias, de aproximadamente 13,5 $\mathrm{g}$, encontradas por Gazziero et al. (2004) e por Barizon e Fernandes (2000), o que permite inferir que esses genótipos apresentaram boa adaptabilidade às condições edafoclimáticas deste ambiente.

Em condições de restrição hídrica, a planta de soja preferencialmente formará poucos grãos nas vagens fixadas, influenciando diretamente na produtividade de grãos da cultura, ou seja, quanto melhor for o desenvolvimento da cultura, melhor será o enchimento de grãos nas vagens, havendo também uma maior massa de cem grãos, que influenciará diretamente na produtividade da cultura (LIMA, 2001). Um dos aspectos relevantes da avaliação desse parâmetro é a relação entre a maior massa de cem grãos e a maior produtividade de grãos ser estabelecida pela mesma cultivar de soja, a BRS 245, que obteve massa e produtividade média de 21,70 g e 3.383,33 Kg ha ${ }^{-1}$, respectivamente.

Em relação à produtividade de grãos, os genótipos avaliados não apresentarem diferenças significativas entre si $(p>0,05 \%)$, e o valor médio para os genótipos avaliados nesta região foi de $3.057,04 \mathrm{Kg}_{\text {ha }}{ }^{-1}$, demonstrandose semelhantes em relação à produtividade média nacional e do Centro-Oeste, que está em torno de $3.000 \mathrm{Kg} \mathrm{ha}^{-1}$ (CONAB, 2011).

O genótipo BRS 245 foi o que apresentou maior valor de produtividade, com uma média aproximada de $3.383,33 \mathrm{~kg}$ ha ${ }^{-1}$, porém não se diferiu estatisticamente dos demais, indicando, assim, que todos os materiais avaliados se adaptaram muito bem às condições edafoclimáticas de Aquidauana e que, a princípio, esta região tem potencial para o cultivo da soja. 


\section{Conclusão}

Os genótipos de soja analisados não diferiram estatisticamente entre si para os parâmetros produtividade e massa de cem grãos, apresentando valores semelhantes à produtividade média nacional para essa cultura.

O desempenho dos genótipos avaliados indica que, inicialmente, as condições edafoclimáticas de Aquidauana, situada na região do ecótono Cerrado-Pantanal, são favoráveis ao cultivo da soja.

\section{Referências}

ARAÚJOJUNIOR, O.; LAZARINI, E.; MERCANDALLI, L. H.; OLIVEIRA, W. A. S.; MELO, C. L. P. Avaliação de cultivares de soja em sistema convencional de cultivo na região do cerrado. Pesquisa Agropecuária Brasileira, Ilha Solteira, v. 21, n. 4, p. 10-14, 2009.

ARGENTA, G.; SILVA, P. R. F.; BORTOLINI, C. G.; FORSTHOFER, E. L.; MANJABOSCO, E. A.; BEHEREGARAY NETO, V. Resposta de híbridos simples de milho à redução do espaçamento entre linhas. Pesquisa Agropecuária Brasileira, Brasília, v. 36, n. 1, p. 71-78, 2001.

BARIZON, R. R. M., FERNANDES, D. M. Nutrição e produção da soja, em sistema de plantio direto, em função de calagem superficial e palhada de brizantão (Brachiaria brizantha). In: FERTBIO, 2000, Santa Maria, CD-ROM, Anais... Santa Maria: Universidade Federal de Santa Maria, 2000..

CERVIERI FILHO, E. Desempenho de plantas oriundas de sementes de alto e baixo vigor dentro de uma população de soja. 2005. 42 p. Tese (Doutorado em Ciências) - Programa de Pós-graduação em Ciências e Tecnologia de Sementes, Universidade Federal de Pelotas, Pelotas, RS, 2005.

CONAB. Companhia Nacional de Abastecimento. Acompanhamento da safra Brasileira - Grãos - safra 2010/2011 - Sétimo Levantamento, abril/2011. Disponível em: <http://www.conab.gov.br/OlalaCMS/uploads/arquivos/11_04_07_11_02_42_boletim_abril-2011. pdf $>$. Acesso em: 05 maio 2012.

EMBRAPA. Sistema brasileiro de classificação de solos. 2. ed. Rio de Janeiro: Embrapa/CNPS, 2006. 306 p.

EMBRAPA AGROPECUARIA OESTE. Tecnologia de produção de soja: Mato Grosso e Mato Grosso do Sul, safra 2008/2009. Maracaju: EMBRAPA, 2009. 197p.

EMBRAPA SOJA. Tecnologias de produção de soja - Região central do Brasil - 2004. Brasília, 2004. Disponível em: <http://www.cnpso.embrapa.br/producaosoja/Sojano Brasil.htm>. Acesso em: 05 maio 2012.

FUNDAÇÃO MS. Produtividade e outras características das cultivares da soja. Boletim de pesquisa de soja - 2009, Chapadão do Sul, n. 9, 2009, 229p.

GAZZIERO, D. L. P.; VARGAS, L.; ROMAN, E. S. Manejo e controle de plantas daninhas em soja. In: VARGAS,
L.; ROMAN, E. S. Manual de manejo e controle de plantas daninhas. Bento Gonçalves: Embrapa Uva e Vinho, 2004, p. 595-635.

IBGE. Cidades, Aquidauana-MS. Produção Agrícola municipal, 2010. Disponível em: <http://www.ibge. gov.br/cidadesat/topwindow.htm?1>. Acesso em: 07 maio 2011.

LIMA, E. V. Alterações dos atributos químicos do solo e resposta da soja à cobertura vegetal e à calagem superficial na implantação do sistema de semeadura direta. 125p. Dissertação (Mestrado) - Universidade Estadual Paulista, Botucatu, 2001.

NAVARRO JÚNIOR, H. M.; COSTA, A. C. Contribuição relativa dos componentes do crescimento para produção de grãos de soja. Pesquisa Agropecuária Brasileira, Brasília, v. 37, n. 2, 2002.

PEIXOTO, C. P; STEELE, C. C.; GRABAU, L. J. Épocas de semeadura e densidade de plantas de soja: I. Componentes da produção e rendimento de grãos. Scientia Agrícola, Piracicaba, v. 57, n. 1, p. 89-96, 2000.

QUEIROZ, E. F.; NEUMAIER, N.; TORRES, E.; PEREIRA, L. A. G.; BIANCHETTI, A.; TERAZAWA, F.; PALHANO, J. B.; YAMASHITA, J. Recomendações técnicas para a colheita mecânica. In: MIYASAKA, S.; MEDINA, J. C. (Ed.). A soja no Brasil. Campinas: ITAL, 1981, p. 701-10.

ROCHA, R. N. C.; PELUZIO, J. M.; BARROS, H. B.; FIDELIS, R. R.; JUNIOR, H. P. S. Comportamento de cultivares de soja em diferentes populações de plantas, em Gurupi, Tocantins. Revista Ceres, Gurupi, TO, v. 48, n. 279, p. 529-537, 2001.

SANTOS, J. A.; JULIATTI, F. C.; SANTOS, V. A.; POLIZEL, A. C.; JULIATTI, F. C.; HAMAWAKI, O. T. Caracteres epidemiológicos e uso da análise de agrupamento para resistência parcial à ferrugem da soja. Pesquisa Agropecuária Brasileira, Brasília, v. 42, n. 3, p. 443-7, 2007.

SCHIAVO, J. A.; PEREIRA, M. G.; MIRANDA, L. P. M.; DIAS NETO, A. H.; FONTANA, A. Caracterização e classificação de solos desenvolvidos de arenitos da formação Aquidauana-MS. Revista Brasileira de Ciência do Solo, Viçosa, v. 34, n. 03, p. 881-889, 2010.

SCHUCH, L. O. B.; KOLCHINSKI, E. M.; FINATTO, J. A. Qualidade fisiológica da semente e desempenho de plantas isoladas em soja. Revista Brasileira de Sementes, Capão do Leão, v. 31, n. 1, p. 144-149, 2009.

SEDIYAMA, T.; PEREIRA, M. G.; SEDIYAMA, C. S.; GOMES, J. L.L. Cultura da soja. Parte I, Viçosa: UFV, 1985.

VERNETTI JUNIOR, F. J.; FRAGA, M. S.; NUNES, T. L. Avaliação de cultivares de soja do grupo de maturidade seis tolerantes ao Glifosato da rede soja sul de pesquisa na Embrapa clima temperado. In: REUNIÃO DE PESQUISA DE SOJA DA REGIAO SUL, 38., 2010, Cruz Alta, RS. Resumos... Cruz Alta: Fundação Centro de Experimentação e Pesquisa, 2010, p. 41-44.

YOKOMIZO, G. K. Interação genótipos $x$ ambientes em topocruzamentos de soja tipo alimento com tipo grão. 170 f. Tese (Doutorado) - Escola Superior de Agricultura Luis de Queiroz, Piracicaba, 1999. 